\title{
Muscular Dystrophy-Dystroglycanopathy (Congenital with Brain and Eye Anomalies) Type A, 4
}

National Cancer Institute

\section{Source}

National Cancer Institute. Muscular Dystrophy-Dystroglycanopathy (Congenital with

Brain and Eye Anomalies) Type A, 4. NCI Thesaurus. Code C126741.

An autosomal recessive muscular dystrophy caused by mutations in the gene encoding fukutin (FKTN). It is associated with characteristic brain and eye malformations, seizures, and mental retardation. 